\title{
A CORRELATION BETWEEN THE HISTOLOGY OF REGENERATED BONE IN AUGMENTED SOCKETS AND IMPLANT STABILITY QUOTIENTS. A CLINICAL AND HISTOLOGICAL RANDOMIZED STUDY
}

\author{
Karim Mohamed Abdel Mohsen*, Waleed Mohamed Abbas** and Moustafa Sayed Taha***
}

\begin{abstract}
Purpose: to correlate between the newly formed bone in different augmented extraction sockets and implant stability quotients, in-favor of reaching the preferred socket augmentation material following application of either platelet-rich fibrin (L-PRF) or Xenograft as augmentation materials or either leaving the sockets non-augmented for enhancement of new bone formation, using histologic assessment and implant stability assessment following implant placement.
\end{abstract}

Methodology: This study was conducted on 27 patients (19 females and 8 males) with age range of (23-49 years), the mean age was $(37,5 \pm 5)$, with 42 fresh extraction sockets in the esthetic zone (13 first premolars, 13 second premolars, 5 canines, 5 lateral incisors and 6 central incisors). Patients were randomly allocated to one of three main groups (A, B, C) which were further divided into six subgroups according to time of implant placement: Group A3: $(n=7)$, Group A6 (n=7), where L-PRF was applied alone immediately after extraction. Group B3 (n=7), Group B6 (n=7): in which Bio-Oss was placed immediately after extraction. Group C3 ( $n=7)$, Group C6 (n=7): in which sockets were left un-augmented. All groups were assessed using resonance frequency analysis (RFA) for implant stability, and histologically where core biopsies were collected at time of implant placement. Correlation was done between the two methods of assessment to reach the preferred augmentation material for bone enhancement.

Results: There was a statistically significant direct (positive) correlation between bone formation \% using Hematoxylin and Eosin (H\&E) stain and Implant Stability Quotient (ISQ) scores after 6 months in control group. An increase in bone formation \% is associated with an increase in ISQ scores and vice versa. There was no statistically significant correlation between bone formation $\%$ using H\&E stain and ISQ scores in all other groups or subgroups.

Conclusion: PRF in the amount used in the current study had a negligible impact on the overall bone quantity in post-extraction sockets or implant stability, leaving sockets un-augmented for six months or more is preferred where bone quality and implant stability are enhanced.

KEY WORDS: L-PRF, Xenograft, Socket augmentation, Implant placement, RFA.

\footnotetext{
* Lecturer of Oral \& Maxillofacial Surgery, Faculty of Dentistry, AinShams University

** Lecturer of Oral \& Maxillofacial Surgery, Faculty of Dentistry, AinShams University

*** Lecturer of Oral Medicine, Periodontology and Oral Diagnosis, Faculty of Dentistry, AinShams University
} 


\section{INTRODUCTION}

The alveolar process is a tooth dependent tissue. Furthermore, alveolar bone volume and shape is determined by the form of the teeth, axis of eruption and inclination ${ }^{(1)}$.

Resorption and bone atrophy are the main challenging consequences following tooth extraction, especially in the esthetic zone. It poses a challenge in clinical practice and is critical for successful implant-supported prostheses in the anterior maxilla as mentioned by Buser et al and Belser et al ${ }^{(2,3)}$.

As documented in the literature, the resorption of the buccal compartment is more pronounced than that of the lingual/palatal portion. Also the process of remodeling continues after the termination of de novo bone formation in the socket(s) ${ }^{(4)}$.

A controlled clinical study by Lekovic and his colleagues, have documented an average 4.0 to 4.5 $\mathrm{mm}$ of horizontal bone resorption following routine atraumatic tooth extraction ${ }^{(4,5)}$.

Many factors were reported to affect the rate and amount of bone loss, and the patient not aware or not informed about, but over time consequences will occur, and cause changes in bone integrity. Such factors are categorized as patient related factors: gender, hormones, smoking, metabolism, parafunction, ill-fitting dentures, time period dentures are worn, facial type (brachiocephalic vs. dolichocephalic) and surgical technique related factors: flapless surgical technique, location of edentulous site, single versus multiple extractions, immediate implant placement and the use of reconstructive technology ${ }^{(6)}$.

The application of reconstructive technologies at fresh extraction sites is one of the most important factors, hence; reducing the need for tissue augmentation which will further affect both implantation and esthetics at this site. These procedures have collectively been termed alveolar ridge preservation (ARP) or socket augmentation ${ }^{(7)}$.
Xenogenic graft is the commonly used bone graft which is bovine-derived an-organic bone matrix material. Bio-Oss ${ }^{\circledR}$, is a deproteinized, sterilized xenograft so can be used without causing a host immune response ${ }^{(8)}$. It is physically and chemically identical to natural human bone mineral, that's why it is a highly effective osteoconductive material ${ }^{(9)}$.

Choukroun et al. (2001 in France) introduced platelet rich fibrin (L-PRF), a second-generation platelet concentrate that improves healing of both hard and soft tissues ${ }^{(10,11)}$. It consists of high concentrations of collected platelets, which allow slow release of growth factors (GFs) ${ }^{(12)}$.

PRF and platelet concentrates were studied in different studies as a sinus augmentation material, or soft tissue enhancing material and used in combination with other grafting materials for hard tissue enhancement, where PRF has been used successfully in a series of clinical trials to treat periodontal defects as conducted by Sharma and Pradeep, it could be used as a guided tissue regeneration (GTR) membrane to affect periodontal regeneration in three wall bony defects and degree II furcation lesions ${ }^{(13,14)}$. Only few studies used it as a socket augmentation material ${ }^{(15-18)}$.

\section{Methodology}

The age of the selected candidates was greater than 18 years. The selected individuals have been allocated randomly into one of the following three groups: Group A: comprised patients with 14 extraction sockets, where L-PRF was applied immediately after extraction, and it was stabilized using 4-0 polyglactin vicryl resorbable sutures. Group B: comprised patients with 14 extraction sockets, in which Bio-Oss Xenograft small particles $(0.25-1 \mathrm{~mm})$ was placed immediately after extraction. The extraction socket was then sealed with collagen plug, this in turn was stabilized by 4-0 polyglactin vicryl resorbable sutures. Group C: comprised patients with 14 extraction sockets underwent the extraction procedure without 
further surgical maneuvers and the sockets were left to heal by secondary intention (no compression of sockets was performed) and the retractable gingiva was stabilized using polyglactin vicryl 4-0.

A preoperative periapical radiographs for preassessment of cases, in addition to provisional restorations were done for space maintainance and esthetic considerations. A silicon/resin stent had been prepared before extraction, including a slot parallel to the long axis of the tooth to be extracted. It helps in proper identification of the socket site during biopsy for standardization.

\section{Surgical procedure}

Surgical technique involved two phases:

Phase one: Atraumatic extraction and augmentation. Phase two: Core biopsy harvest and implant placement after three months for groups (A3, B3, C3) and after six months for groups (A6, B6, C6), and ISQ score measurements with the Osstell Mentor RF Analyzer (Ostell USA).

Phase I: Surgical extraction and blood collection: Extraction had been carried out atraumatically, under local anesthesia and aseptic conditions for all groups:

- All patients rinsed their mouths with Chlorohexidine 2\% (Hexitol: Arab Drug CompanyADCO-A.R.E.) for 2 minutes.

- At the extraction site, $2 \%$ Mepivacaine with 1:200,000 levonordeferin (Mepivacaine-L, Alexandria Co, Egypt) local anesthesia was administered.

- Extraction was carried out using periotomes for teeth luxation, and forceps for delivery of teeth with minimal trauma to the surrounding bone and tissues.

- The socket was completely curetted of all soft tissue remnants after extraction and irrigated with normal saline solution. The socket was carefully inspected to check the integrity of labial bone plate, and if there was a bony wall defect or loss during the extraction procedure, the patient was excluded from the study.

\section{Group A: Platelet rich fibrin preparation} (L-PRF): L-PRF prepared according to Choukroun's technique: disinfection of the site with alcohol swabs for at least 30 seconds. A tourniquet was applied to the upper arm region to facilitate collection of blood samples. $10 \mathrm{ml}$ blood was drawn into standard glass/silica coated blood collection tubes using IV cannula at the radial or the anti-cubital angle, and immediately centrifuged at $3000 \mathrm{rpm}$ for 10 minutes where an appropriate balance weight was achieved by putting an opposite tube filled with water.

At the end of the centrifugation process, three layers were formed in the tube:

- At the bottom of the tube, red cells were concentrated.

- The intermediate fraction was a dense PRF.

- The superficial layer was platelet-poor plasma (PPP).

PRF was easily separated from the red corpuscles using a sterile tweezers and scissors, then compressed to be easily applied to the extraction sites and stabilized by suturing at the extraction site using polyglactin vicryl 4-0.

Group B: Bio-Oss xenograft (Geistlich Pharma AG, Wolhuson, Switzerland) small particles (0.25$1 \mathrm{~mm}$ ) impregnated with sterile saline to aid in handling of the graft, was applied to the extraction socket to the bone level, then stabilized in place and protected from soft tissue migration by a collagen plug (Ora-plug, Zimmer dental, Carlsbad CA) which sutured in place using polyglactin vicryl 4-0.

Group C: after the extraction procedure, approximating soft tissue margins was done using 4-0 polyglactin suture. 
Phase II: Core biopsy harvest and implant placement: The extraction site was surgically reentered after either three or six months for taking core biopsies and implant placement:

- All patients rinsed their mouths with Chlorohexidine $2 \%$.

- Local anesthesia was administered using $2 \%$ Mepivacaine with 1:200000 levonordeferin.

- A crestal incision and a full thickness mucoperiosteal flap was reflected. The prefabricated surgical stent was secured in place then a trephine bur with $2.3 \mathrm{~mm}$ internal diameter and $3.0 \mathrm{~mm}$ external diameter (Helmut ZEPF, Germany) was used to harvest the core biopsy guided by the prefabricated stent.

- Implant (Tapered internal implant, Biohorizons Inc, Alabama, USA) with standardized length and diameter $(3.8 \mathrm{~mm}$ diameter and $12 \mathrm{~mm}$ length) was inserted at the osteotomy site $1 \mathrm{~mm}$ below the bone crest level. If an osseous fenestration occurred during implant placement, guided bone regeneration was performed using a xenograft material and a collagen membrane. The cover screw was attached to the implant fixture after implant stability measurement was taken. The flap was then repositioned and sutured using 4-0 polyglactin vicryl suture material.

\section{Implant stability measurements}

The primary stability for each implant was measure by the RFA technique: implant stability quotient (ISQ) values were collected by means of a transducer attached to the implant via a screw and a frequency response analyzer. Clinical measurements for the values of the implant stability quotient (ISQ) of the installed implants were collected at three months for groups (A3, B3, and C3) and six months for groups (A6, B6, and C6), tabulated and later correlated with the histologic results, and then statistically analyzed using results of Spearman's correlation coefficient for the correlation between both results.

\section{Histological examination}

The collected core specimens were submitted for Histologic evaluation in Pathology department laboratory Faculty of Medicine, Ain Shams University. Samples were dissected from socket core biopsies, fixed, decalcified and sections of $4 \mu \mathrm{m}$ thicknesses were cut in a longitudinal plane using microtome (Leica, Watzlar, Germany). All specimens were stained using hematoxlin and eosin (H\&E). The stained sections were assessed and bone quality measurements were performed by using the image analyzer system Leica DFC 295 microsystem and Leica Q Win and Q Go programs image analysis software at the Histomorphometry Laboratory, Histology Department, Faculty of Medicine, Ain Shams University.

\section{Statistical analysis}

The significance level was set at $\mathrm{P} \leq 0.05$. Statistical analysis was performed with IBM SPSS Statistics for Windows, Version 23.0. Armonk, NY: IBM Corp. P- value: level of significance:

Results of Spearman's correlation coefficient was used for the correlation between bone formation $\%$ using H\&E stain and ISQ scores.

\section{RESULTS}

All patients completed the course of the study successfully. None of the cases developed infection, or signs and symptoms of pain.

\section{Morphometric analysis}

At three months; the mean area percentage for the newly formed bone was lowest at PRF group.

After six months; PRF group showed lower amount of newly formed bone, compared to Xenograft group. 
At three months; the mean area of newly formed bone for A3 made up to19.59 $\pm 6.21 \%$, B3 $35.44 \pm 10.33 \%$ and for C3 $34.58 \pm 10.13 \%$, where PRF group showed the lowest amount among the study groups after three months. Besides; there was high statistical significant difference between A3, $\mathrm{B} 3$ and $\mathrm{C} 3(\mathrm{P}=0.01)$, where $\mathrm{PRF}$ group represented the lowest percentage.

After six months; the mean area of newly formed

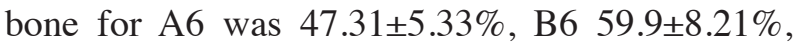
while C6 59.25 $\pm 6.35 \%$. Xenograft showed the largest amount which were comparable to the control group, while PRF group showed the least amount, there were high statistical significant difference between the study groups $(\mathrm{P}=0.007)$, suggesting new bone formation in all subgroups after six months, where Xenograft group represented the highest percentage.

\section{Implant stability analysis}

After three months RFA readings mean was $65 \pm 28.66$ in PRF group, $60 \pm 21.3$ in Xenograft and $72 \pm 2.2$ in the control group, the negative control showed the highest value while there were no statistically significant differences between them.

After six months RFA readings' mean was $74 \pm 5.1$ in PRF group, $65 \pm 8.9$ in Xenograft and $69 \pm 8.18$ in the control group, where PRF group showed the highest values while there were no statistically significant differences between them.

Correlation between Implant stability and

\section{histologic analysis}

There was a statistically significant direct (positive) correlation between bone formation \% using H\&E stain and ISQ scores after 6 months in control group. An increase in bone formation \% is associated with an increase in ISQ scores and vice versa.

There was no statistically significant correlation between bone formation \% using H\&E stain and ISQ scores in all other groups or subgroups (table 1, figure 1).
TABLE (1) Results of Spearman's correlation coefficient for the correlation between bone formation \% using $\mathrm{H} \& \mathrm{E}$ stain and ISQ scores

\begin{tabular}{|l|l|c|c|}
\hline \multirow{3}{*}{ Group } & Subgroup & $\begin{array}{c}\text { Correlation } \\
\text { coefficient }(\mathbf{0})\end{array}$ & $\boldsymbol{P}$-value \\
\hline \multirow{3}{*}{ 6 months } & Control & $\mathbf{- 0 . 3 6 0}$ & $\mathbf{0 . 4 2 7}$ \\
\cline { 2 - 4 } & Xenograft & $\mathbf{- 0 . 2 5 0}$ & $\mathbf{0 . 5 8 9}$ \\
\cline { 2 - 4 } & PRF & $\mathbf{- 0 . 4 0 0}$ & $\mathbf{0 . 3 7 4}$ \\
\hline \multirow{3}{*}{ Overall } & Control & $\mathbf{0 . 8 5 7}$ & $\mathbf{0 . 0 1 4}$ \\
\cline { 2 - 4 } & Xenograft & $\mathbf{- 0 . 2 5 2}$ & $\mathbf{0 . 5 8 5}$ \\
\cline { 2 - 4 } & PRF & $\mathbf{- 0 . 5 5 9}$ & $\mathbf{0 . 1 9 2}$ \\
\cline { 2 - 4 } & Xentrol & $\mathbf{0 . 0 3 7}$ & $\mathbf{0 . 8 9 9}$ \\
\cline { 2 - 4 } & PRF & $\mathbf{- 0 . 0 0 2}$ & $\mathbf{0 . 9 9 4}$ \\
\hline \multirow{2}{*}{} & Penraft & $\mathbf{- 0 . 3 9 7}$ & $\mathbf{0 . 1 6 0}$ \\
\hline
\end{tabular}

\section{*: Significant at $P \leq 0.05$}

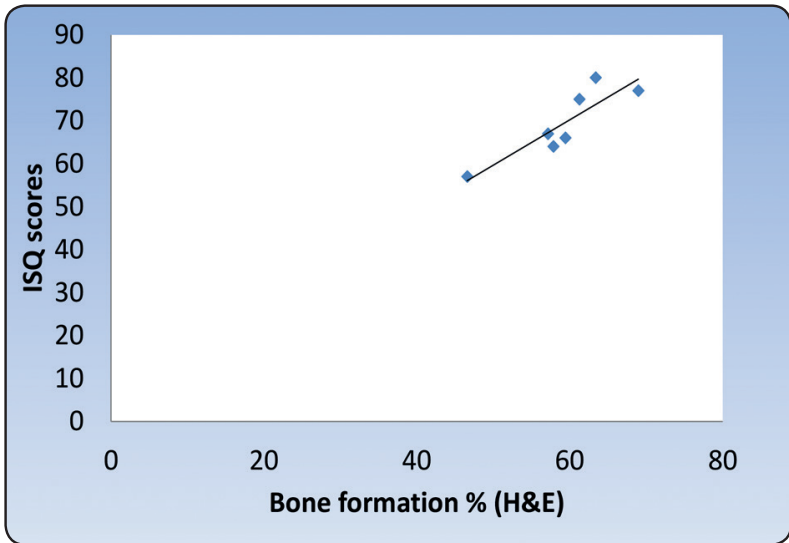

Fig. (1) Scatter diagram representing direct correlation between bone formation \% using H\&E stain and ISQ scores after 6 months in control group.

\section{DISCUSSION}

Bone resorption and surrounding gingival collapse following tooth (teeth) extraction is inevitable, especially in the esthetic zone where it poses a challenge in clinical practice and is critical for successful implant-supported prostheses in the anterior maxilla as mentioned by Belser et al ${ }^{(2)}$.

Smukler et al ${ }^{(19)}$ reported that resorption is more pronounced in the mandible than in the maxilla, also 
the buccal side loses more volume than the lingual. The greatest amount of bone loss occurs in the horizontal and vertical dimensions, mainly on the facial aspect ${ }^{(5,20)}$.

To elucidate the full depth of this clinical dilemma, the physiology of extraction socket healing requires reviewing.

It was demonstrated that the typical healing time for a socket is 12 weeks. The return to normal bony architecture and organization is not completed at 24 weeks after the extraction ${ }^{(21-24)}$.

In accordance, the samples in this study were grouped into two different timelines (three and six months), to investigate the best timing for implant placement in regards to bone quality after socket augmentation.

Hence; many techniques were advocated for ARP or socket augmentation. These include atraumatic extraction $^{(25-27)}$, socket augmentation ${ }^{(28-30)}$ and surgical maneuvers associated with implant placement.

Various authors have supported coverage of xenografts as Barone et al who mentioned that there were a significantly higher percentage of trabecular bone and total mineralized tissue in socket augmentation sites compared to extraction-alone ${ }^{(28)}$.

Many authors recommended using collagenbased barrier membranes to contain the graft material until the epithelial closure occur so protect the graft material from epithelial infiltration during the healing ${ }^{(5,31)}$.

Autologous materials proposed for socket augmentation include a wide variety of options. Choukroun et al ${ }^{(10,32)}$ introduced platelet rich fibrin (L-PRF), a second-generation platelet concentrate, that claimed to improve healing of both hard and soft tissues. ${ }^{(16,18,33-35)}$.

Despite; the wide acceptance for socket augmentation procedures in the literature, the agreement had been opposed. Aroujo et al ${ }^{(36)}$, reported a foreign body reaction against the graft material in the early stages of socket healing, causing delayed healing, and showed that there were no added benefit from socket augmentation, this idea was also supported by Becker et al and Buser et al ${ }^{(37,38)}$.

A systematic review was conducted to assess the quality of post extraction healing following PRF application. The study concluded that; the seven studies that fit the selection criteria suffered from author bias ${ }^{(39-44)}$. In addition, various authors have demonstrated that after a 12-weeks healing period, natural bone formation is adequate for implant placement $^{(45,46)}$.

Besides; bone grafting material resorbs with time, and has a negative impact on the bone implant contact and primary implant stability ${ }^{(37,47)}$. Carmagnola et al and Molly et al ${ }^{(47,48)}$ reported that socket augmentation jeopardized early implant osseointegration and/or primary stability.

Several methods were used to investigate bone resorption. These include clinical, radiographic and histological measurements. Many studies were carried out on implant stability measurements that have a direct relation with bone quality ${ }^{(49,50)}$.

Dental implants with higher primary stability, that is often referred to as clinically stable implants, has higher percentages of osseointegration, hence primary implant stability is being considered as a key factor and major indicator in the success of dental implant treatment ${ }^{(51)}$. The assessment of implant success by evaluation of primary stability was in agreement with Meredith et al ${ }^{(52)}$, Friberg et al..$^{(53)}$ and Rasmusson el al. ${ }^{(54)}$.

Although several techniques and materials for socket augmentation were reported the data remains inconclusive with a strong controversial background. The histologic outcomes for intra socket grafts using different materials and its effect on implant primary stability remain vague ${ }^{(7,29,55)}$. 
Research focusing on L-PRF as a new innovation for socket augmentation was limited.

The current study was designed to shed light on the effect of different grafting materials on post extraction socket healing and its effect on implant stability. The study groups selected to use the most commonly advocated materials. Xenograft which was the preferred non-autogenous graft by many authors ${ }^{(47,55,56)}$ and PRF which is a recent autologous affordable, easily prepared grafting

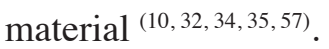

For the simplicity of deduction, the results were displayed as a correlation between both histologic and ISQ results:

At three months; the mean area percentage for the newly formed bone was lowest at PRF group.

After six months; PRF group showed lower amount of newly formed bone, compared to Xenograft group.

Several studies had previously reported similar outcomes. Jambhekar et al (58-61) review study, reported histologic analysis for sockets core biopsies augmented with Bio-Oss ${ }^{\circledR}$ after $\geq 12$ weeks, showed that the newly formed bone was $35.72 \%$ and there was large amount of bone graft remnants. In accordance with our study Xenograft group was $35.44 \pm 10.33 \%$ with also large amount of bone graft remnants.

Fabbro and Bortolin ${ }^{(34)}$, reviewed the effect of platelet concentrates on extraction socket healing. Seven split-mouth randomized studies met the inclusion criteria. Three studies reported no significant effect of platelet concentrate on bone regeneration ${ }^{(39,40,42)}$. The remaining four reported a favorable effect on healing ${ }^{(44,62-64)}$.

After three months RFA readings mean was $65 \pm 28.66$ in PRF group, 60 \pm 21.3 in Xenograft and $72 \pm 2.2$ in the control group, the negative control showed the highest value followed by PRF followed by Xenograft group and there were no statistically significant differences between them. These results were in agreement with Atieh el al. (65) in his systematic review whom found no effect for socket preservation on implant primary stability.

After six months RFA readings' mean was $74 \pm 5.1$ in PRF group, $65 \pm 8.9$ in Xenograft and $69 \pm 8.18$ in the control group, where PRF group showed the highest values followed by control group followed by Xenograft group, and there were no statistically significant differences between them. In agreement with Vignoletti el al. ${ }^{(66)}$ in his systematic review whom found no effect for socket preservation on implant primary stability.

There was a statistically significant direct (positive) correlation between bone formation \% using H\&E stain and ISQ scores after 6 months in control group. An increase in bone formation \% is associated with an increase in ISQ scores and vice versa. There was no statistically significant correlation between bone formation \% using H\&E stain and ISQ scores in all other groups or subgroups.

Many authors found a positive correlation between bone density measured histologically and ISQ values, showing a significant positive correlation between high-density bone and higher ISQ values ${ }^{(67,68)}$.

Correlation of Bone Volume and ISQ Values Over Time done by Christian et al ; there was a positive correlation between ISQ and BV (r 0.366; n 40; $P$ 0.02). At 3 weeks, there was a positive correlation between ISQ and BV (r 0.465; n 40; P 0.003) $)^{(69)}$.

Ostman et al described a significant correlation between clinically assessed bone density and ISQ values ${ }^{(70)}$. Aksoy et al and Huwiler et al could not establish any correlation between histologically evaluated BV and ISQ values ${ }^{(71,72)}$.

Data show that RFA is correlated to the length of implants used. ${ }^{(73)}$ where it is indicating the resistance to bending load. ${ }^{(51)}$ Our study 
showed that the socket preservation didn't improve the primary stability nor the bone quantity. In a recent systematic review published by Cochrane Collaboration, Ateih et al ${ }^{(65)}$ in 2015 concluded that, no technique is considered better than another regarding ARP and it's still not clear which technique would provide the most predictable results and hence, it's still early to draw any conclusions with regard to the best surgical technique. Bone healing in post extraction socket is governed by several factors including: the position of tooth in the jaw (mandible or maxilla - posterior or anterior), thickness of buccal plate at the extraction socket and the technique utilized in extraction (flap vs. flapless), while Xenograft remains the most commonly used to enhance bone remodeling in extraction socket as compared to PRF which is proven to have negligible impact on the bone healing after extraction socket. All these materials and studies were done to enhance bone quality, and so positively affect implant primary stability, which considered as a method for bone quality assessment through using different methods, in particular resonance frequency analysis (RFA), which seems to be the most trustworthy ${ }^{(74,75)}$. Although histological assessment is the most accurate among methods of assessment where it estimate the quantity and quality of bone, there is a large defect regarding this assessment for augmented sockets as Jambheker stated in his review study ${ }^{(55)}$, so we used this method for assessment to give an additive value, in correlation with implant stability measurements.

\section{CONCLUSION}

- Total amount of newly formed bone is still controversial after three months.

- Total amount of newly formed bone was more pronounced at six-month interval with decrease in the graft remnants.

- $\quad$ PRF in the amount used, had a minimal effect on the quantity of newly formed bone, even after six months.
- Correlation between histologic and implant stability results showed no statistical significant difference after three months for socket augmentation.

- Correlation between histologic and implant stability results showed statistical significant difference at control after six months for socket augmentation.

- Leaving sockets un-augmented is the best after six months regarding quality of bone, which positively affect the implant 1ry stability.

\section{RECOMMENDATIONS}

To obtain more reliable results:

1- Additional studies with larger patient sample size are necessary in order to identify the specific trends and risk parameters that should be evaluated before any alveolar ridge preservation procedure.

2- Conduction of a split mouth study so that the position of the tooth and thickness of the buccal plate, are standardized for more reliable results.

3- PRF may be used in combination with other types of bone grafts in order to maximize its effect on bone.

4- The correlation between different implant stability measurements and bone quality will give an additive value regarding timing of implant placement.

\section{REFERENCES}

1. Schroeder HE: Development, structure, and function of periodontal tissues. The periodontium: Springer, 1986, 23-323

2. Belser UC, Grütter L, Vailati F, et al:: Outcome evaluation of early placed maxillary anterior single-tooth implants using objective esthetic criteria: a cross-sectional, retrospective study in 45 patients with a 2-to 4-year follow-up using pink and white esthetic scores. Journal of periodontology. 2009, 80:140-151. 
3. Buser D, Martin W, Belser UC: Optimizing esthetics for implant restorations in the anterior maxilla: anatomic and surgical considerations. International Journal of Oral \& Maxillofacial Implants. 2004, 19.

4. Schropp L, Wenzel A, Kostopoulos L, Karring T: Bone healing and soft tissue contour changes following singletooth extraction: a clinical and radiographic 12-month prospective study. International Journal of Periodontics \& Restorative Dentistry. 2003, 23.

5. Lekovic V, Camargo PM, Klokkevold PR, et al.: Preservation of alveolar bone in extraction sockets using bioabsorbable membranes. Journal of periodontology. 1998, 69:1044-1049.

6. Farina R, Trombelli L: Wound healing of extraction sockets. Endodontic Topics. 2011, 25:16-43.

7. Darby I, Chen ST, Buser D: Ridge preservation techniques for implant therapy. Int J Oral Maxillofac Implants. 2009, 24:260-271.

8. Hislop W, Finlay P, Moos K: A preliminary study into the uses of anorganic bone in oral and maxillofacial surgery. British Journal of Oral and Maxillofacial Surgery. 1993, 31:149-153.

9. Palmieri A, Pezzetti F, Brunelli G, et al.: Anorganic bovine bone (Bio-Oss) regulates miRNA of osteoblast-like cells. International Journal of Periodontics \& Restorative Dentistry. 2010, 30 .

10. Choukroun J, Adda F, Schoeffler C, Vervelle A: Une opportunité en paro-implantologie: le PRF. Implantodontie. 2001, 42:e62.

11. Choukroun J, Braccini F, Diss A, et al.: Influence of platelet rich fibrin (PRF) on proliferation of human preadipocytes and tympanic keratinocytes: A new opportunity in facial lipostructure (Coleman's technique) and tympanoplasty? Revue de laryngologie-otologie-rhinologie. 2007, 128:27-32.

12. Kang Y-H, Jeon SH, Park J-Y, et al.: Platelet-rich fibrin is a Bioscaffold and reservoir of growth factors for tissue regeneration. Tissue Engineering Part A. 2010, 17:349-359.

13. Sharma A, Pradeep A: Treatment of 3-wall intrabony defects in patients with chronic periodontitis with autologous platelet-rich fibrin: a randomized controlled clinical trial. Journal of periodontology. 2011, 82:1705-1712.

14. Sharma A, Pradeep AR: Autologous platelet-rich fibrin in the treatment of mandibular degree II furcation defects: A randomized clinical trial. Journal of periodontology. 2011, 82:1396-1403.
15. Ehrenfest DMD, Diss A, Odin G, et al.: In vitro effects of Choukroun's PRF (platelet-rich fibrin) on human gingival fibroblasts, dermal prekeratinocytes, preadipocytes, and maxillofacial osteoblasts in primary cultures. Oral Surgery, Oral Medicine, Oral Pathology, Oral Radiology and Endodontics. 2009, 108:341-352.

16. Mazor Z, Horowitz RA, Del Corso M, et al:: Sinus floor augmentation with simultaneous implant placement using Choukroun's platelet-rich fibrin as the sole grafting material: a radiologic and histologic study at 6 months. Journal of periodontology. 2009, 80:2056-2064.

17. A, Choukroun J, Del Corso M, Sammartino G, Ehrenfest DMD: Simultaneous sinus-lift and implantation using microthreaded implants and leukocyte-and platelet-rich fibrin as sole grafting material: a six-year experience. Implant dentistry. 2011, 20:2-12.

18. Hauser F, Gaydarov N, Badoud I, et al.: Clinical and histological evaluation of postextraction platelet-rich fibrin socket filling: a prospective randomized controlled study. Implant dentistry. 2013, 22:295-303.

19. Smukler H, Landi L, Setayesh R: Histomorphometric evaluation of extraction sockets and deficient alveolar ridges treated with allograft and barrier membrane: a pilot study. International Journal of Oral \& Maxillofacial Implants. $1999,14$.

20. Van der Weijden F, Dell'Acqua F, Slot DE: Alveolar bone dimensional changes of post-extraction sockets in humans: a systematic review. Journal of clinical periodontology. 2009, 36:1048-1058.

21. Amler MH: The time sequence of tissue regeneration in human extraction wounds. Oral Surgery, Oral Medicine, Oral Pathology. 1969, 27:309-318.

22. Chan H-L, Lin G-H, Fu J-H, Wang H-L: Alterations in bone quality after socket preservation with grafting materials: a systematic review. International Journal of Oral \& Maxillofacial Implants. 2013, 28.

23. Evian C, Rosenberg E, Coslet J, Corn H: The osteogenic activity of bone removed from healing extraction sockets in humans. Journal of periodontology. 1982, 53:81-85.

24. Trombelli L, Farina R, Marzola A, et al.: Modeling and remodeling of human extraction sockets. Journal of clinical periodontology. 2008, 35:630-639.

25. Araújo MG, Silva JCC, Mendonça AF, Lindhe J: Ridge alterations following grafting of fresh extraction sockets 
in man. A randomized clinical trial. Clinical oral implants research. 2015, 26:407-412.

26. Fickl S, Zuhr O, Wachtel H, et al.: Dimensional changes of the alveolar ridge contour after different socket preservation techniques. Journal of clinical periodontology. 2008, 35:906-913.

27. Gupta D, Gundannavar G, Chinni DD, Alampalli RV: Ridge Preservation done Immediately followingExtraction using Bovine Bone Graft, Collagen Plugand Collagen Membrane. International Journal of Oral Implantology and Clinical Research. 2012, 3:8-16.

28. Barone A, Aldini NN, Fini M, et al.: Xenograft versus extraction alone for ridge preservation after tooth removal: a clinical and histomorphometric study. Journal of periodontology. 2008, 79:1370-1377.

29. Iasella JM, Greenwell H, Miller RL, et al.: Ridge preservation with freeze-dried bone allograft and a collagen membrane compared to extraction alone for implant site development: a clinical and histologic study in humans. Journal of periodontology. 2003, 74:990-999.

30. Okabe K, Nakagawa K, Yamamoto E: Factors affecting the occurrence of bacteremia associated with tooth extraction. International journal of oral and maxillofacial surgery. 1995, 24:239-242.

31. Lekovic V, Kenney E, Weinlaender M, et al.: A bone regenerative approach to alveolar ridge maintenance following tooth extraction. Report of 10 cases. Journal of periodontology. 1997, 68:563-570.

32. Dohan Ehrenfest DM, Del Corso M, Diss A, Mouhyi J, Charrier J-B: Three-dimensional architecture and cell composition of a Choukroun's platelet-rich fibrin clot and membrane. Journal of periodontology. 2010, 81:546-555.

33. Pradeep A, Rao NS, Agarwal E, et al.: Comparative evaluation of autologous platelet-rich fibrin and plateletrich plasma in the treatment of 3-wall intrabony defects in chronic periodontitis: a randomized controlled clinical trial. Journal of periodontology. 2012, 83:1499-1507.

34. Del Fabbro M, Bortolin M, Taschieri S: Is autologous platelet concentrate beneficial for post-extraction socket healing? A systematic review. International journal of oral and maxillofacial surgery. 2011, 40:891-900.

35. Suttapreyasri S, Leepong N: Influence of platelet-rich fibrin on alveolar ridge preservation. Journal of Craniofacial Surgery. 2013, 24:1088-1094.
36. Araújo M, Linder E, Lindhe J: Effect of a xenograft on early bone formation in extraction sockets: an experimental study in dog. Clinical oral implants research. 2009, 20:1-6.

37. Becker W, Clokie C, Sennerby L, Urist MR, Becker BE: Histologic findings after implantation and evaluation of different grafting materials and titanium micro screws into extraction sockets. Journal of periodontology. 1998, 69:414-421.

38. Buser D, Hoffmann B, Bernard Jp, et al.: Evaluation of filling materials in membrane-protected bone defects. A comparative histomorphometric study in the mandible of miniature pigs. Clinical oral implants research. 1998, 9:137-150.

39. Gürbüzer B, Pikdöken L, Tunalı M, et al.: Scintigraphic evaluation of osteoblastic activity in extraction sockets treated with platelet-rich fibrin. Journal of oral and maxillofacial surgery. 2010, 68:980-989.

40. Gürbüzer B, Pikdöken L, Urhan M, Süer BT, Narin Y: Scintigraphic Evaluation of Early Osteoblastic Activity in Extraction Sockets Treated With Platelet-Rich Plasma. Journal of oral and maxillofacial surgery. 2008, 12:24542460 .

41. Moghe S, Saini N, Moghe A: Platelet-rich plasma in periodontal defect treatment after extraction of impacted mandibular third molars. National journal of maxillofacial surgery. 2012, 3:139.

42. Mozzati M, Martinasso G, Pol R, et al.: The impact of plasma rich in growth factors on clinical and biological factors involved in healing processes after third molar extraction. Journal of Biomedical Materials Research Part A. 2010, 95:741-746.

43. Alissa R, Esposito M, Horner K, Oliver R: The influence of platelet-rich plasma on the healing of extraction sockets: an explorative randomised clinical trial. European journal of oral implantology. 2010, 3 .

44. Vivek G, Rao BS: Potential for osseous regeneration of platelet rich plasma: a comparitive study in mandibular third molar sockets. Journal of maxillofacial and oral surgery. 2009, 8:308-311.

45. Nahles S, Nack C, Gratecap K, et al.: Bone physiology in human grafted and non-grafted extraction sockets-an immunohistochemical study. Clinical oral implants research. 2013, 24:812-819. 
46. Neiva R, Duarte F, Pagni G, et al.: Analysis of Tissue Neogenesis in GBR-treated Extraction Sockets: Clinical, Histological and MicroCT Results. Int J Periodontics Restorative Dent. 2011,31:457-469.

47. Carmagnola D, Adriaens P, Berglundh T: Healing of human extraction sockets filled with Bio-Oss ${ }^{\circledR}$. Clinical oral implants research. 2003, 14:137-143.

48. Molly L, Vandromme H, Quirynen M, et al.: Bone formation following implantation of bone biomaterials into extraction sites. Journal of periodontology. 2008, 79:1108-1115.

49. Alghamdi HS: Methods to Improve Osseointegration of Dental Implants in Low Quality (Type-IV) Bone: An Overview. Journal of functional biomaterials. 2018, 9:7.

50. Rashad MSM: Assessment Of Primary Stability Of Implants Inserted Into Sockets Augmented With Anorganic Bovine Bone Mineral Or Platelet Rich Fibrin. clinical study, Ain-Shams University: 2016

51. Sennerby L, Meredith N: Implant stability measurements using resonance frequency analysis: biological and biomechanical aspects and clinical implications. Periodontology 2000. 2008, 47:51-66.

52. Meredith N, Alleyne D, Cawley P: Quantitative determination of the stability of the implant-tissue interface using resonance frequency analysis. Clinical oral implants research. 1996, 7:261-267.

53. Friberg B, Sennerby L, Linden B, Gröndahl K, Lekholm U: Stability measurements of one-stage Brånemark implants during healing in mandibles: a clinical resonance frequency analysis study. International journal of oral and maxillofacial surgery. 1999, 28:266-272.

54. Rasmusson L, Meredith N, Kahnberg Ke, Sennerby L: Effects of barrier membranes on bone resorption and implant stability in onlay bone grafts. An experimental study. Clinical oral implants research. 1999, 10:267-277.

55. Jambhekar S, Kernen F, Bidra AS: Clinical and histologic outcomes of socket grafting after flapless tooth extraction: a systematic review of randomized controlled clinical trials. Journal of Prosthetic Dentistry. 2015, 113:371-382.

56. Artzi Z, Tal H, Dayan D: Porous bovine bone mineral in healing of human extraction sockets. Part 1: histomorphometric evaluations at 9 months. Journal of periodontology. 2000, 71:1015-1023.

57. Zhang Y, Tangl S, Huber CD, et al.: Effects of Choukroun's platelet-rich fibrin on bone regeneration in combination with deproteinized bovine bone mineral in maxillary sinus augmentation: a histological and histomorphometric study. Journal of Cranio-maxillo-facial Surgery. 2012, 40:321328.

58. Heberer S, Al-Chawaf B, Jablonski C, et al.: Healing of ungrafted and grafted extraction sockets after 12 weeks: a prospective clinical study. International Journal of Oral \& Maxillofacial Implants. 2011, 26.

59. Cardaropoli D, Roffredo A, Cardaropoli G: Socket preservation using bovine bone mineral and collagen membrane: a randomized controlled clinical trial with histologic analysis. International Journal of Periodontics \& Restorative Dentistry. 2012, 32.

60. Lindhe J, Cecchinato D, Donati M, Tomasi C, Liljenberg B: Ridge preservation with the use of deproteinized bovine bone mineral. Clinical oral implants research. 2014, 25:786-790.

61. Shakibaie-M B: Comparison of the effectiveness of two different bone substitute materials for socket preservation after tooth extraction: a controlled clinical study. International Journal of Periodontics \& Restorative Dentistry. 2013,33 .

62. Anitua E: Plasma rich in growth factors: preliminary results of use in the preparation of future sites for implants. International journal of Oral and maxillofacial Implants. 1999, 14:529-535.

63. Rutkowski JL, Johnson DA, Radio NM, Fennell JW: Platelet rich plasma to facilitate wound healing following tooth extraction. Journal of Oral Implantology. 2010, 36:11-23.

64. Sammartino G, Tia M, Marenzi G, et al.: Use of autologous platelet-rich plasma (PRP) in periodontal defect treatment after extraction of impacted mandibular third molars. Journal of oral and maxillofacial surgery. 2005, 63:766-770.

65. Atieh MA, Alsabeeha NH, Payne AG, et al.: Interventions for replacing missing teeth: alveolar ridge preservation techniques for dental implant site development. Cochrane Database of Systematic Reviews. 2015.

66. Vignoletti F, Matesanz P, Rodrigo D, et al.: Surgical protocols for ridge preservation after tooth extraction. A systematic review. Clinical oral implants research. 2012, 23:22-38.

67. Turkyilmaz I, Sennerby L, McGlumphy EA, Tözüm TF: Biomechanical aspects of primary implant stability: a human cadaver study. Clinical implant dentistry and related research. 2009, 11:113-119. 
68. Sim CP, Lang NP: Factors influencing resonance frequency analysis assessed by Osstell ${ }^{\mathrm{TM}}$ mentor during implant tissue integration: I. Instrument positioning, bone structure, implant length. Clinical oral implants research. 2010, 21:598-604.

69. Makary C, Rebaudi A, Sammartino G, Naaman N: Implant primary stability determined by resonance frequency analysis: correlation with insertion torque, histologic bone volume, and torsional stability at 6 weeks. Implant dentistry. 2012, 21:474-480

70. Östman P-O, Hellman M, Wendelhag I, Sennerby L: Resonance frequency analysis measurements of implants at placement surgery. International Journal of Prosthodontics. 2006, 19.

71. Aksoy U, Eratalay K, Tözüm T: The possible association among bone density values and histomorphometric evalu- ations of dental implant osteotomy sites: A preliminary study. Implant Dent. 2009, 18:316-325.

72. Huwiler M, Pjetursson BE, Bosshardt D, Salvi G, Lang NP: Resonance frequency analysis in relation to jawbone characteristics and during early healing of implant installation.Clinical oral implants research. 2007, 18:275-280

73. Degidi M, Daprile G, Piattelli A: Primary stability determination by means of insertion torque and RFA in a sample of 4,135 implants. Clinical implant dentistry and related research. 2012, 14:501-507.

74. Davies J: Mechanisms of endosseous integration. International Journal of Prosthodontics. 1998, 11.

75. Spadaro J, Albanese S, Chase S: Electromagnetic effects on bone formation at implants in the medullary canal in rabbits. Journal of Orthopaedic Research. 1990, 8:685-693. 